\title{
Análise introdutória dos determinantes da eleição de Dilma
}

\author{
Ana Elisa Gonçalves Pereira* \\ Cláudio Shikida ${ }^{* *}$ \\ Luciano Nakabashi ${ }^{* * *}$
}

\begin{abstract}
RESUMO - O presente artigo apresenta evidências empíricas de que o programa Bolsa Família teve um papel preponderante na eleição da candidata do PT, Dilma Rousseff, em 2010, e que este efeito foi superior ao do desempenho econômico favorável durante o governo Lula. Os resultados da análise apontam para uma votação mais expressiva em Dilma nos municípios com menor nível de escolaridade, dando suporte à hipótese de Zucco (2008) de que essas populações tendem a ser mais dependentes do Estado e, portanto, a primar pela manutenção do poder vigente.
\end{abstract}

Palavras-chave: Eleições presidenciais. Bolsa Família. Proporção de votos.

\section{INTRODUÇÃO}

Os elementos que determinam o sucesso de um candidato nas eleições presidenciais são analisados com muita determinação pelos membros de sua equipe e pelos integrantes dos seus respectivos partidos políticos, pois eles desejam maximizar as chances de sucesso eleitoral. No entanto, esse é um tema de interesse mais amplo, pois envolve interação entre agentes econômicos, sociais e políticos, e os resultados desse processo geram efeitos relevantes em toda a trajetória de desenvolvimento de uma nação. Essas interações e seus efeitos são foco de estudo de cientistas políticos e sociais, além de despertarem um interesse cada vez maior por parte de pesquisadores que utilizam ferramentais provenientes das ciências econômicas.

No entanto, os elementos que determinam os resultados de uma eleição mudam consideravelmente dependendo do país, do momento histórico, das condições sociais, econômicas, políticas e dos candidatos que pretendem ocupar o cargo. No Brasil, essa disputa vem se polarizando, nas últimas duas décadas, em torno de dois partidos políticos: PT e PSDB.

Nas últimas três eleições presidenciais, ocorreram transformações relevantes no eleitorado que determinou a escolha do presidente, sobretudo entre 2002 e 2006 . No pleito que

\footnotetext{
* Mestranda em Desenvolvimento Econômico pela Universidade Federal do Paraná. Endereço eletrônico: anaelisagpereira@gmail.com.

** Doutor em Economia pela Universidade Federal do Rio Grande do Sul. É professor do IBMEC-MG. Endereço eletrônico: cdshikida@gmail.com.

*** Doutor em Economia pelo Centro de Desenvolvimento e Planejamento Regional/Universidade Federal de Minas Gerais. É professor do Departamento de Economia da Universidade Federal do Paraná e pesquisador do CNPq. Endereço eletrônico: luciano.nakabashi@gmail.com.
} 
levou à reeleição de Luiz Inácio Lula da Silva, a maior parcela dos votos foi obtida nas regiões menos desenvolvidas do Brasil, ao contrário de 2002.

Em 2010, a candidata Dilma Rousseff, que no início de sua campanha apresentou intenção de voto pouco expressiva nas pesquisas eleitorais, ganhou força, levou a disputa para o segundo turno e venceu. Esse resultado foi fortemente atribuído pela mídia ao apoio irrestrito do então presidente Lula - que terminou o seu segundo mandato com elevado índice de aprovação $^{1}$-, ao razoável crescimento econômico apresentado em seus oito anos de governo e à difusão do programa Bolsa Família durante a última gestão.

No presente estudo, ao notar que o perfil do eleitorado petista se assemelha ao de 2006 e não ao de 2002, busca-se investigar de forma introdutória qual hipótese se ajusta melhor aos dados municipais. Ou seja, objetiva-se averiguar quais aspectos são mais relevantes na determinação da fração de votos em Dilma nos municípios.

As evidências apresentadas denotam que programas dessa natureza (cash transferprogra$m s)$, que se difundiram na América Latina em meados de 1990, independentemente do sucesso na manutenção do crescimento econômico e na redução da pobreza e da desigualdade, foram fundamentais para o sucesso nas urnas.

Além desta introdução, o presente artigo conta com outras duas seções. A segunda seção faz uma resenha de trabalhos teóricos e empíricos que abordam a relação entre desempenho econômico e resultados eleitorais. A seção seguinte fornece uma análise introdutória das variáveis utilizadas na análise empírica.

\section{LITERATURA PRÉVIA: DETERMINANTES ECONÔMICOS DE RESULTA- DOS ELEITORAIS}

A discussão acerca da crescente extensão dos programas de transferência de renda durante os dois mandatos de Luiz Inácio Lula da Silva, sobretudo do programa Bolsa Família², e o desempenho eleitoral do Partido dos Trabalhadores nas últimas três eleições presidenciais tornaram-se foco de debate acadêmico nos últimos anos. Esta literatura, ainda incipiente, tem buscado precisar os fatores socioeconômicos mais relevantes empiricamente na determinação do vote share dos presidenciáveis. Com especial enfoque nos programas do tipo cash transfers,

1 Ferreira, Sakurai e Oliveira (2011) sugerem que fatores econômicos foram elementos essenciais na determinação dos elevados índices de aprovação do governo Lula.

2 Segundo o Ministério de Desenvolvimento Social (MDS), o Bolsa Família é um programa de transferência direta de renda com condicionalidades, que beneficia famílias em situação de pobreza e de extrema pobreza. O programa integra o Fome Zero, que tem como objetivo assegurar o direito humano à alimentação adequada. Contempla mais de 12 milhões de famílias com renda familiar de até R \$ 140 por pessoa. A renda, o número e a idade dos filhos determinam o valor do benefício, que antes do reajuste de março de 2011, variava entre R\$22 e R\$200. 
alguns economistas e cientistas políticos têm encontrado em bases de dados brasileiros municipais ou estaduais um campo fértil para mensurar possíveis determinantes dos resultados eleitorais da última década.

De acordo com essa literatura, pode-se verificar uma reversão no padrão de votação em 2006, em relação à eleição anterior: o perfil do eleitorado de Lula se modifica substancialmente (HUNTER; POWER, 2007; CARRARO et al., 2007; CANÊDO-PINHEIRO, 2009). Enquanto em 2002 Lula apresentou uma votação mais expressiva nas regiões mais desenvolvidas do país, mais urbanizadas, com renda mais elevada e maior nível de escolaridade, em 2006 foram os municípios menos desenvolvidos e mais dependentes do Estado que apresentaram uma fração de votos maior em Lula.

Esse cenário tem sido atribuído a fatores distintos na literatura. Hunter e Power (2007) apontam três prováveis explicações para tal padrão eleitoral, sendo que elas não são excludentes. Uma possibilidade é que as populações mais carentes, com menor nível educacional e menor acesso à informação, não tiveram amplo acesso aos escândalos de corrupção do primeiro mandato de Lula ou não deram um peso relevante a tais escândalos no momento de escolher o voto. Uma segunda explicação levantada é a percepção de melhora nas condições de vida das classes menos favorecidas, durante os anos de 2002 a 2006, traduzida em gratidão à política de Lula e do PT (hipótese esta defendida pelos autores). A terceira possibilidade é que esses votos sejam reflexo da massificação de programas de transferência de renda como o Bolsa Família.

Canêdo-Pinheiro (2009) faz uso desse terceiro argumento. O autor evidencia um impacto significativo da extensão do programa Bolsa Família sobre os votos obtidos por Lula em 2006 nos municípios, muito superior ao efeito do desempenho econômico favorável. Em cidades com renda per capita menor, mais famílias em situação de pobreza ou extrema pobreza - ou seja, aquelas que têm maior parcela de sua população contemplada por programas de transferência direta de renda - apostaram mais fortemente na continuidade do PT no poder para garantir a manutenção dos benefícios provenientes desses programas. Além disso, Canêdo-Pinheiro (2009) ressalta a hipótese de Zucco (2008) de que as regiões menos desenvolvidas e com menor nível de escolaridade tendem a depender mais do Estado e a prezar pela manutenção do poder nas mãos do mesmo grupo.

Zucco (2008) identifica uma regularidade neste padrão: o candidato da situação apresentou um desempenho eleitoral mais satisfatório nas regiões menos desenvolvidas em todos os turnos de todas as eleições de 1994 a 2006, independentemente do partido, das propostas e da ideologia deste candidato. O autor aponta ainda a imensa dificuldade em se dissociar os efeitos do crescimento econômico e dos programas de transferência de renda nas regiões mais pobres. 
O autor argumenta que, em regiões carentes, pouca atividade econômica privada é desenvolvida e a percepção dos eleitores em relação à situação econômica está fortemente atada ao seu bemestar econômico, decorrente primordialmente dos benefícios recebidos do governo.

Ao contrário de Canêdo-Pinheiro (2009), Marques et al. (2009) e Abensur, CribariNeto e Menezes (2007), o trabalho de Carraro et al. (2007) contesta a relevância do programa Bolsa Família para a reeleição de Lula em 2006. Utilizando o método de econometria espacial, os autores encontram evidências de que o sucesso eleitoral do PT nas regiões menos desenvolvidas do país decorreu de mudanças favoráveis às populações de baixa renda no mercado de trabalho, controle inflacionário e sucesso exportador brasileiro durante o primeiro mandato de Lula. Para os autores, a votação de Lula foi mais expressiva nos municípios mais pobres, mais desiguais e com mais analfabetos, mas sem fortes evidências de que o programa Bolsa Família em si tenha exercido impacto significativo sobre o resultado eleitoral.

\section{ANÁLISE EMPÍRICA INTRODUTÓRIA}

Nota-se, no Gráfico 1, uma elevada correlação entre o percentual de votos obtidos por Lula em 2006 e o vote share de Dilma em 2010 nos municípios. Há duas possibilidades (não mutuamente exclusivas, com provável elevada correlação entre elas) para esta semelhança no padrão de votação: os mesmos fatores sociais e econômicos que levaram as regiões menos desenvolvidas a eleger Lula foram importantes na eleição de Dilma (nomeadamente, o crescimento da economia e a grande expansão dos programas de transferência de renda); e/ou o eleitorado de Lula se manteve fiel, e o apoio incondicional do então presidente à candidata do PT favoreceu, por si só, a votação em Dilma, independentemente das condições econômicas e da obtenção de benefícios. Neste caso, o eleitorado interpretou que apesar da troca de presidente, o governo Dilma seria de continuidade em relação ao seu antecessor. Ferreira, Sakurai e Oliveira (2011) sugerem que uma associação desses dois efeitos foi relevante para o sucesso de Dilma nas eleições.

O Gráfico 1 traz o diagrama de dispersão entre a proporção municipal dos votos válidos obtidos por Dilma no segundo turno das eleições presidenciais de 2010 (eixo vertical) e o vote share de Lula no segundo turno das eleições de 2006 (eixo horizontal), o que indica a importância do apoio do então presidente Lula e a crença de que sua candidata daria continuidade a suas políticas econômicas e sociais. 
GRÁFICO 1 - PROPORÇÃO MUNICIPAL DOS VOTOS VÁLIDOS DILMA SEGUNDO TURNO (2010) E VOTE SHARE LULA SEGUNDO TURNO (2006)

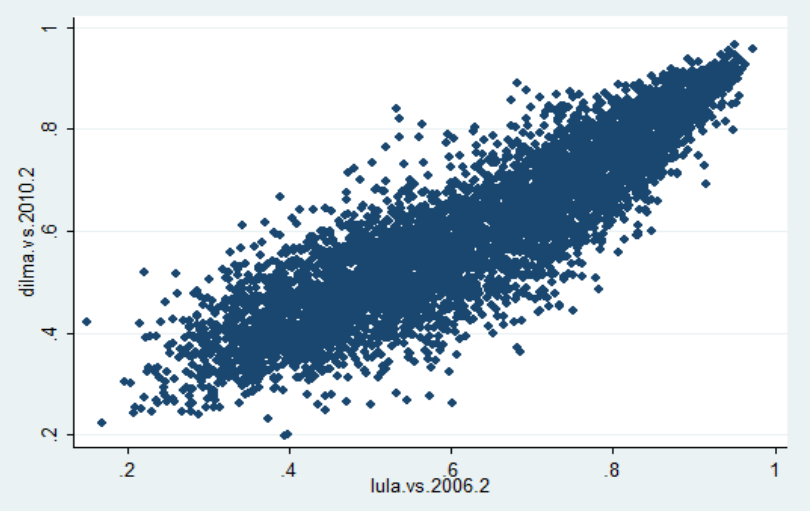

FONTE: Elaboração própria.

Observa-se, nos Gráficos 2 e 3 a seguir, grande correlação negativa entre a proporção de votos na candidata do PT e o nível de desenvolvimento dos municípios (escolaridade média e IDH):

GRÁFICO 2 - PROPORÇÃO MUNICIPAL DOS VOTOS VÁLIDOS DILMA SEGUNDO TURNO (2010) E ESCOLARIDADE

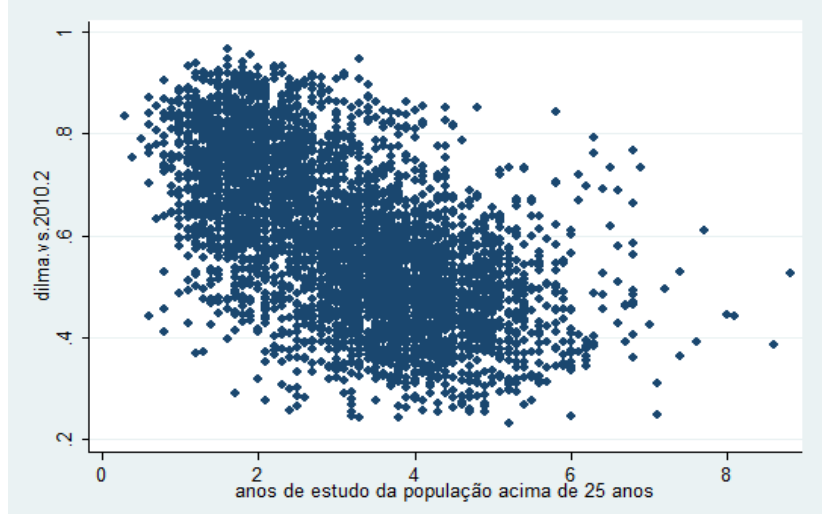

FONTE: Elaboração própria.

GRÁFICO 3 - PROPORÇÃO MUNICIPAL DOS VOTOS VÁLIDOS DILMA SEGUNDO TURNO (2010) E IDH (2000)

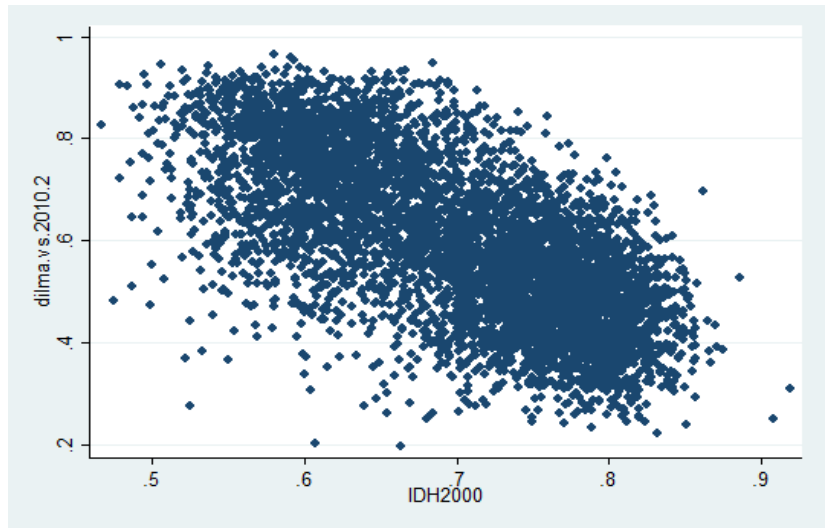

FONTE: Elaboração própria. 
Os três diagramas apresentados levam a crer que o cenário eleitoral de 2010 se assemelha fortemente ao de 2006: municípios menos desenvolvidos (menor IDH em 2000) e com menor escolaridade média da população acima de 25 anos renderam maior proporção de votos à candidata da situação. Naqueles municípios com maiores níveis de escolaridade e desenvolvimento, aparentemente prevaleceu o desejo de alternância de poder, refletido na maior proporção de votos em José Serra, um resultado similar ao ocorrido na reeleição do presidente Lula, conforme apontado na literatura revisada.

Conforme sinalizam os diagramas de dispersão que seguem (Gráficos 4 e 5), pode-se observar uma correlação clara entre a proporção de famílias beneficiadas pelo programa Bolsa Família e a votação em Dilma. Já a possível relação entre os votos no PT e o crescimento econômico dos municípios durante a "Era Lula" não é tão evidente (Gráfico 6).

GRÁFICO 4 - PROPORÇÃO MUNICIPAL DOS VOTOS VÁLIDOS DILMA SEGUNDO TURNO (2010) E ALCANCE DO BOLSA FAMÍLIA

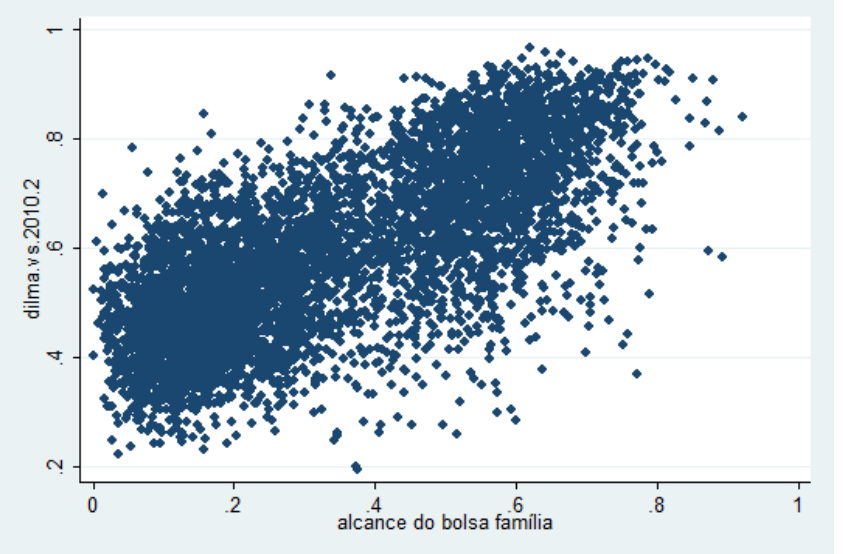

FONTE: Elaboração própria.

GRÁFICO 5 - PROPORÇÃO MUNICIPAL DOS VOTOS VÁLIDOS DILMA SEGUNDO TURNO (2010) E RECURSOS DO BOLSA FAMÍLIA PER CAPITA

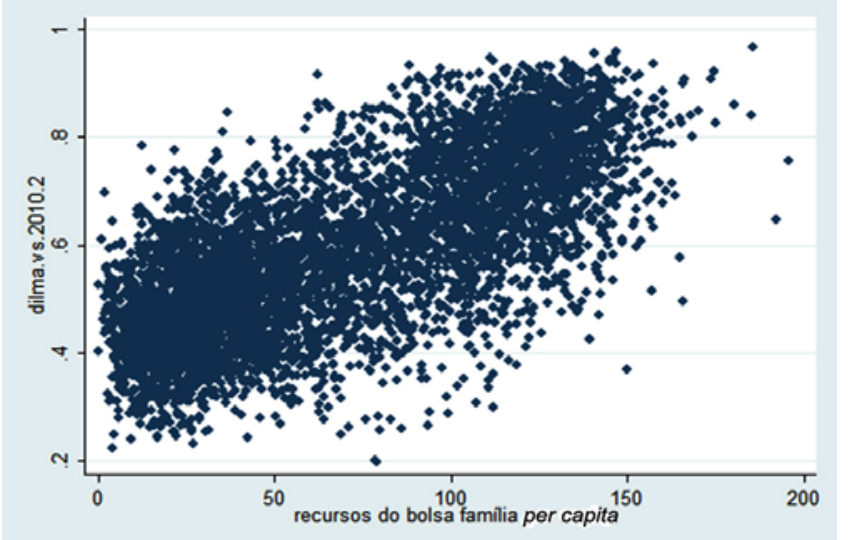

FONTE: Elaboração própria. 
GRÁFICO 6 - PROPORÇÃO MUNICIPAL DOS VOTOS VÁLIDOS DILMA SEGUNDO TURNO (2010) E CRESCIMENTO DO PIB PER CAPITA (2002 A 2008)

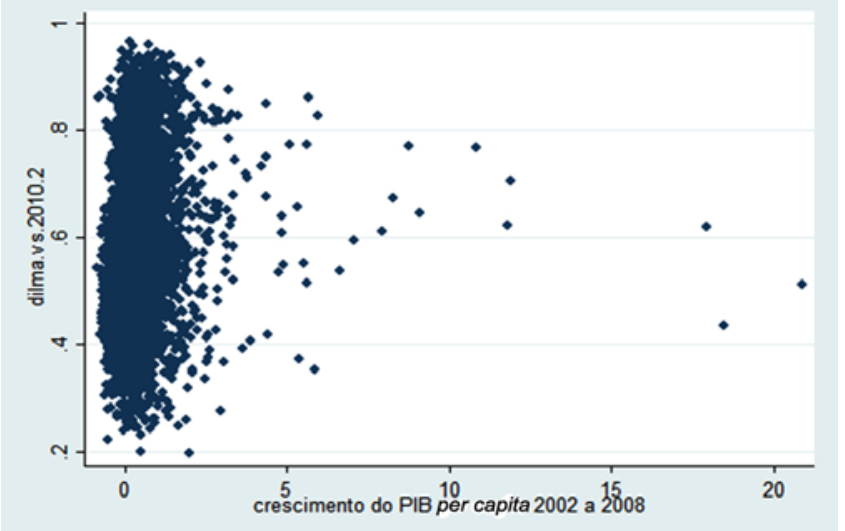

FONTE: Elaboração própria.

Pode-se ressaltar, adicionalmente, a aparente correlação, um pouco mais sutil, entre a proporção de não brancos na população e a votação em Dilma (Gráfico 7). Esta relação pode ser resultado das políticas de promoção da igualdade racial desenvolvidas durante a última gestão do PT ou apenas uma consequência da correlação existente entre raça e variáveis socioeconômicas.

GRÁFICO 7 - PROPORÇÃO MUNICIPAL DOS VOTOS VÁLIDOS DILMA SEGUNDO TURNO (2010) E NÃO BRANCOS NA POPULAÇÃO

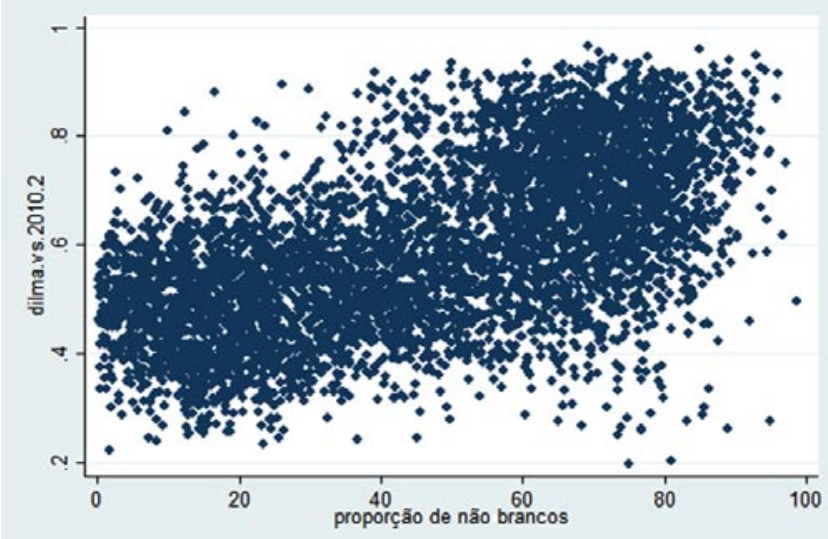

FONTE: Elaboração própria.

Vale destacar que as correlações acima indicadas podem ser espúrias. Para contornar essa possibilidade, na sequência do trabalho, buscamos evidências mais concretas acerca da influência das variáveis selecionadas sobre a proporção de votos por meio da regressão beta.

\section{CONSIDERAÇÕES FINAIS}

Neste artigo, buscou-se fazer uma análise introdutória das variáveis que afetaram o desempenho da então candidata à presidência da República em 2010. 
O alcance do programa Bolsa Família - que hoje vai de pouco mais de 0,1\% das famílias, no município menos beneficiado pelo programa, a mais de $92 \%$ das famílias, no município mais beneficiado - aparentemente exerceu papel fundamental na continuidade do PT no poder, conforme a literatura revisada indica, além, claro, das evidências deste trabalho para as eleições de 2010 .

Outro resultado importante é que a proporção de votos municipais no PT apresentou uma grande inércia entre 2006 e 2010, sendo uma evidência da importância do apoio do então presidente Lula à candidata Dilma.

Por fim, o melhor desempenho de Dilma em municípios com menores níveis do índice IDH e de escolaridade dão suporte à hipótese de Zucco (2008) de que as regiões menos desenvolvidas e com menor nível de escolaridade tendem a depender mais do Estado e a prezar pela manutenção do poder nas mãos do mesmo grupo.

\section{REFERÊNCIAS}

ABENSUR, T. C.; CRIBARI-NETO, F.; MENEZES; T. A. Impactos do Programa Bolsa Família nos Resultados das Eleições Presidenciais no Brasil em 2006. In: ENCONTRO NACIONAL DE ECONOMIA, 35., 2007, Recife. Anais... Recife: ANPEC, 2007.

CARRARO, A.; SHIKIDA, C. D.; MONASTERIO, L. M.; ARAUJO JUNIOR, A. F. D.; DAMÉ, O. M. "It is the economy, companheiro!": an empirical analysis of Lula's re-election. Economics Bulletin, v. 29, n. 2, p. 976-991, 2009. Disponível em: <http://www.accessecon. com/Pubs/EB/2009/Volume29/EB-09-V29-I2-P46.pdf>.

CRIBARI-NETO, F.; ZEILEIS, A. Beta Regression in R. Journal of Statistical Software, v. 34, n. 2, p. 1-24, 2010.

CGU - Controladoria Geral da União. Disponível em: < http://www.cgu.gov.br>.

FERREIRA, A. L.; SAKURAI, S. N.; OLIVEIRA, R. Oito anos construindo popularidade. Economia e Tecnologia, Curitiba, volume especial, p. 5-15, 2011.

HUNTER, W.; POWER, T. J. Rewarding Lula: executive power, social policy, and the brazilian elections of 2006. Latin American Politics and Society, v. 49, p. 1-30, 2007.

INSTITUTO BRASILEIRO DE GEOGRAFIA E ESTATÍSTICA (IBGE). Censo 2000. INSTITUTO BRASILEIRO DE GEOGRAFIA E ESTATÍSTICA (IBGE). Censo 2010.

IPEA - Instituto de Pesquisa Econômica Aplicada. Disponível em: <http://www.ipeadata.gov. br>.

MARQUES, R. M. A importância do Bolsa Família nos municípios brasileiros. Cadernos de Estudo: Desenvolvimento Social em Debate - Ministério do Desenvolvimento Social e Combate à Fome, Brasília, n. 1, 2005.

MARQUES, R. M.; LEITE, M. G.; MENDES, A.; FERREIRA, M. R. J. Discutindo o papel do programa Bolsa Família na decisão das eleições presidenciais brasileiras de 2006. Revista de Economia Política, v. 29, p. 114-132, 2009. 
NICOLAU, J. PEIXOTO, V. Uma disputa em três tempos: uma análise das bases municipais das eleições presidenciais de 2006. In: ENCONTRO NACIONAL DA ANPOCS, 31., 2007. Anais...

PNUD: Atlas do desenvolvimento humano no Brasil (software).

TSE - Tribunal Superior Eleitoral. Disponivel em: < http://www.tse.gov.br/>.

ZUCCO, C. The president's 'new' constituency: Lula and the pragmatic vote in Brazil's 2006 presidential elections. Journal of Latin American Studies, v. 40, p. 29-39, 2008. 
